\title{
Value-added Service of Distribution Center on Integrated Cold Chain Performance
}

\author{
Jin-Jin Mou ${ }^{1, *}$, Ying-Mei Jiang ${ }^{1}$ \\ ${ }^{1}$ School of Management, Shandong Vocational University of Foreign Affairs, Weihai 264504, China
}

\begin{abstract}
Different from the previous articles on multi-echelon cold chain system, in addition to traditional transportation/distribution, warehousing and inventory control, DC value-added services, such as joint order processing, product processing and customizing, picking and assorting, joint distribution, etc. are employed to improve the performance of the cold chain system. Case study and sensitivity analysis demonstrate that (1) DC revenue is mainly from processing and customizing service for all kinds of products; (2) Of the value added services, picking and assorting cost has a significant effect on the total profit. These conclusions present good theoretical and managerial insights.
\end{abstract}

\section{Introduction}

It is documented that global food losses have been on the order of $25 \%$ to $50 \%$ of production volumes, caloric content and/or market values depending on the commodity (Gustavsson et al., 2011). It is stated that the loss caused solely by the deterioration of fruits and vegetables is as high as 100 billion RMB per year in China owing to the poor cold chain management.

A "cold chain" is comprised of equipment and processes that keep perishable products under conditioned environment. The storing and distribution environment as well as warehousing technology directly determine the quality and safety of perishable products. In order to keep quality and consuming safety required by end customers and reduce relative logistics cost, especially the deterioration cost, an integrated inventory policy needs to be emphasized among all members in the cold chain. However, in China, except for exports, most of the cold chain inventory and logistics distribution are completed by producers and distributors, such as milk, meat, sea products, fresh fruits and vegetables and so on.

Distribution center (DC) as a third-party logistics, it can not only efficiently links the producers and retailers, but also provide some value-added services. Value-added services refer to unique or specific activities that participating firms can jointly develop to enhance their efficiency and/or effectiveness. Different from traditional logistics service, value-added service is committed to provide customers with additional or special value over basic/standard value (Wang,2018). In most cases, cold chain logistics value-added services cannot be separated from the basic transport and warehousing services. Value added services generally extend the basic services to an integrated service or broader logistics functions, such as joint order processing, product processing and customizing, picking and assorting, joint distribution, program settlement, consulting, strategic alliance, customer service, etc.

It is found that compared with the traditional scenario of all products directly to the customers, the integrated scenario made by DC, achieved significant improvements in areas such as reductions of up to $64 \%$ in number of routes, $53 \%$ in number of visits, $74 \%$ in transport distance, and $63 \%$ in transport time (Bosona et al.,2013). However, over the past two decades, most of the cold chain inventory models are devoted to two-echelon decisions, such as, Yang \& Wee (2000), Das et al. (2013), Rahdar and Nookabadi (2014), Ghiami \& Williams (2015), Chan et al. (2017), Mohammadi et al. (2019), etc. It is in shortage of DC based cold chain system. It is found that three-echelon inventory system with DC is better than a two-echelon system (Wang et al., 2020), yet, the effect of DC value added service on system performance is not concerned.

Motivated by the above background, following questions would be proposed: (1) Will DC operating logistics bring a rise in cold chain profit? (2) How do DC value-added services affect the system profit?

The rest of this paper organized as follows. Section 2 presents the problem description. Section 3 provides numerical analysis. Finally, it summarizes the findings and concludes the potential impacts of this work in section 4 .

\section{Problem description}

Different from the traditional logistics operation by producers as per Fig.1(1), an integrated operation of both the collection and distribution of goods are operated by one DC. The specialized DC could not only achieve economies of scale through consolidated pickup and delivery, but also save the transportation/distribution cost through the multi-temperature joint collection and distribution among all producers and retailers for all kinds of products. Assume that in the system, it is composed of

* Corresponding author: mujinjinde@163.com 
3 cold chain producers, one DC and 2 retailers, as seen in

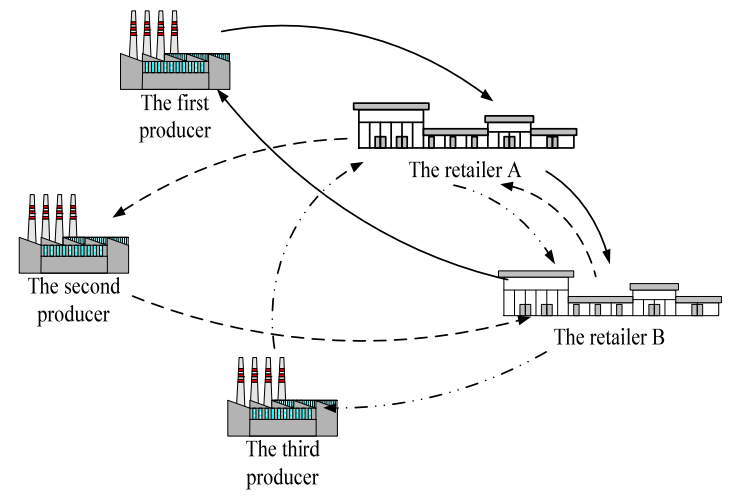

(1) Logistics operation by producers
Fig. 1(2).

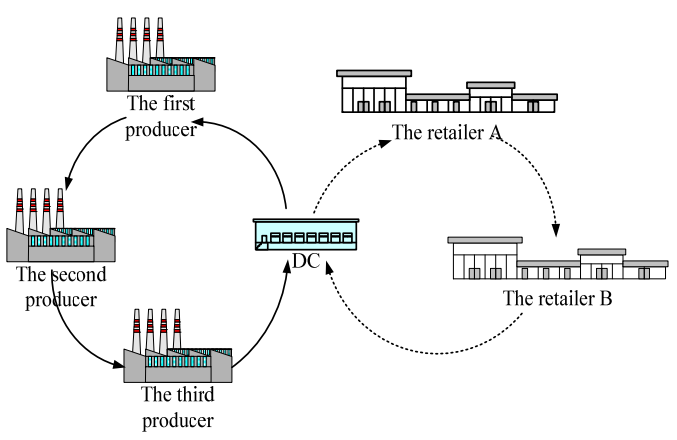

(2) Outsourcing logistics to DC

Fig. 1. Different modes of cold chain logistics operation.

Traditional logistics operation by producers depicted in Fig.1(a) shows that 3 kinds of cold chain products produced by the producers are transported directly to the two retailers, which will lead to higher transportation cost because of smaller quantities of goods moved. On the contrary, outsourcing logistics to DC depicted in Fig.1(2) demonstrated that the ordering information of 2 retailers is gathered and processed by the DC, which is the basis for DC to centralize purchasing from 3 manufacturers and arrange the process of collection, storage, transportation and distribution of the goods to the two retailers. Because of the joint collection and distribution of the goods, the net savings in pickup and delivery of the goods will be less than the increase in warehousing cost.

\section{Case study and analysis}

In this section, we will verify the importance of DC in an three-echelon cold chain system, from two aspects: (1) DC profit source from its value-added services, such as, picking and assorting, processing and customizing, and joint distribution; (2) The effects of DC cost parameters on DC profits.

Based on the study of three-echelon cold chain inventory system(Wang et al., 2020), we investigated a local cold chain system, composed of 3 producers, one distribution center and 2 retailers. The DC is responsible for all the logistics services. In this system, one producer specializes in one kind of cold chain products, expressed as $k$. For example, if $k=2$, it means that the second producer produces the second kind of products. In this study, the meanings of the regarding parameters are defined as, (1) $h_{d k}$ : holding cost per unit time of DC for the $k$ th product; (2) $S_{d}$ : ordering cost per order of the DC; (3) $H_{d}$ : fixed cost per cycle time of warehouse in DC; $(4)_{G_{d}}$ : picking and assorting cost per order of DC; (5) $v_{d k}$ : delivery cost ratio of DC for the $k$ th product and (6) $E_{d k}$ : unit processing and customizing cost per for the $k$ th product. The parameter data of the distribution center is as the Table 1 .

Table 1. Parameter data of the DC.

\begin{tabular}{|c|c|c|c|c|c|c|}
\hline & $S_{d}$ & $H_{d}$ & $G_{d}$ & $E_{d k}$ & $h_{d k}$ & $v_{d k}$ \\
\hline$k=1$ & \multirow{3}{*}{300} & \multirow{3}{*}{200} & \multirow{3}{*}{1500} & 1 & 3 & $8 \%$ \\
\hline$k=2$ & & & & 0.8 & 2 & $7 \%$ \\
\hline$k=3$ & & & & 0.5 & 0.5 & $8 \%$ \\
\hline
\end{tabular}

\subsection{The DC profit sources}

Obtaining the regarding operation cost, and then we get the DC gross profit. DC gross profit from one kind of service means DC income from its service minus its regarding cost. The DC profit sources are as the following Table 2. Table 2 shows DC gross profits from storage, transportation and distribution.

Table 2. The gross profit of DC from services.

\begin{tabular}{|c|c|c|c|c|c|}
\hline & $k=1$ & $k=2$ & $k=3$ & Summation & The proportion \\
\hline $\begin{array}{c}\text { Gross profit from storage } \\
\text { Gross profit from transportation and } \\
\text { distribution }\end{array}$ & 0.4752 & 0.2834 & 0.3565 & 1.1151 & $17.9 \%$ \\
\hline $\begin{array}{c}\text { Gross profit from processing and } \\
\text { customizing }\end{array}$ & 3.1967 & 0.1506 & 0.5067 & 3.8540 & $62.1 \%$ \\
\hline $\begin{array}{c}\text { Summation of gross profit } \\
\text { Total ordering cost }\end{array}$ & 4.6641 & 0.6457 & 0.8945 & 6.2046 & $100 \%$ \\
\hline
\end{tabular}




\begin{tabular}{|c|c|c|c|c|c|}
\hline Total picking and assorting cost & $/$ & $/$ & $/$ & 2.4 & $/$ \\
\hline Total profit & $/$ & $/$ & $/$ & 3.3246 & $/$ \\
\hline
\end{tabular}

Note: The real data $=$ the data in the table $\times \mathrm{e}+004$.

From Table 2, we find that DC gross profit from processing and customizing accounts for a large proportion, then is from DC transportation and distribution, and that from storage downgrades to a small proportion, which coincides the concept of DC value added service and indicates the importance of deep product processing in distribution center.

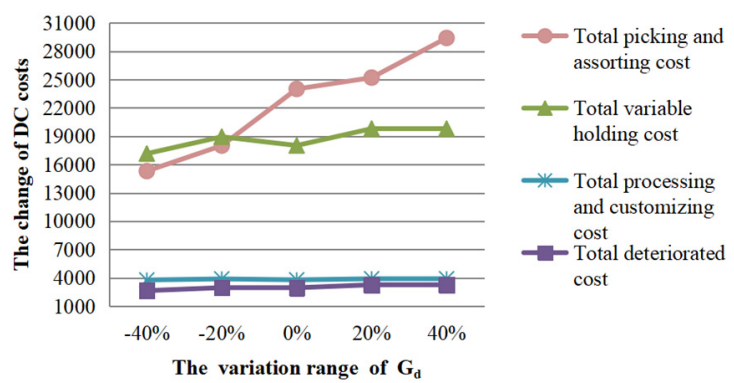

Fig. 2. The effects of $G_{d}$ on DC costs.\#
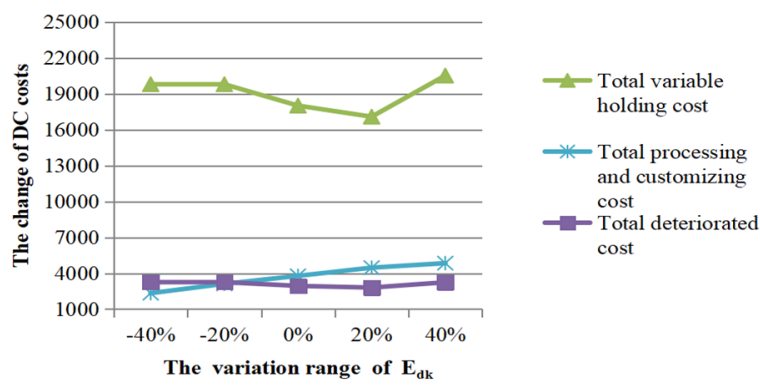

Fig. 4. The effects of $E_{d k}$ on DC costs.\#

As illustrated in Fig.2, DC total picking and assorting cost decreases greatly with the decrease of $G_{d}$. The change of the total variable holding cost is also consistent with the tendency of $G_{d}$ change. The decrease of the total picking and assorting cost and the total variable holding cost contributes to the savings of DC total cost. Thus DC total profit increases with the decrease of $G_{d}$.

From Fig. 3, it reveals that with the decrease of $G_{d}$, DC gross profit from storage is decreased, which certifies that storage has degraded to the basic function of DC warehousing with the decrease of $G_{d}$. Therefore, the application of automatic technology and innovation management in DC picking and assorting activities would help to highlight its value-added services as well as increase DC total profit.

Fig.4 indicates that with the decrease of $E_{d k}$, DC total processing and customizing cost decreases, total variable holding cost increases, and the total deteriorated cost

\subsection{Effects of DC cost parameters}

As DC profit from value-added services accounts for a larger share of its total profit. Thus, DC per unit picking and assorting cost $G_{d}$ and its per unit processing and customizing $\operatorname{cost} E_{d k}$ are chosen for sensitivity analysis.

In order to analyze the effects of $G_{d}$ and $E_{d k}$ on DC cost components and its profit, Fig.2 Fig.5 depict the changes of $G_{d}$ and $E_{d k}$ on some DC cost and its gross profit from services.

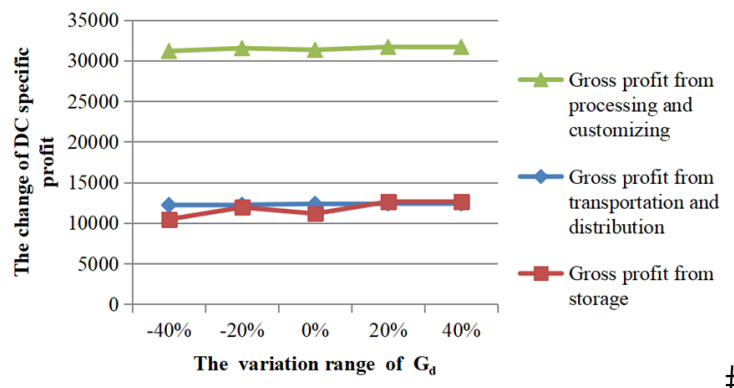

Fig. 3. The effects of $G_{d}$ on DC service gross profit.\#

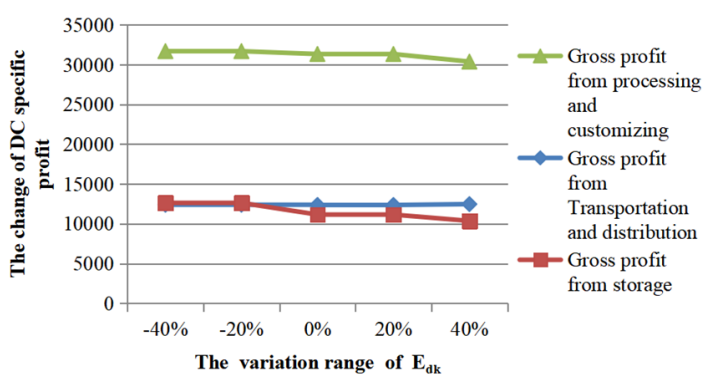

Fig. 5. The effects of $E_{d k}$ on DC service gross profit.\#

remains almost no change. The increase of the total variable holding cost incurred with the decrease of $E_{d k}$ comes from the increase of the replenishment quantity of low-value products.

Fig. 5 shows that DC gross profit from processing and customizing goes upward with the decrease of $E_{d k}$, which indicates that DC profit comes more and more from value added service. On the other hand, it shows that with the decrease of $E_{d k}$, DC gross profit from storage is increased, which means that keeping relatively more quantities moderately processed by producers earns more storage profit, whereas keeping large quantities of relatively primary products gets the lowest storage profit. It proves again that the storage of low products has become the basic function of distribution center.

\section{Conclusion}

This paper proposes an three-echelon cold chain system 
with DC. The major contributions are: (1) DC profit source from its value-added services, such as, picking and assorting, processing and customizing, and joint distribution etc. is demonstrated, (2) The effects of DC cost parameters on DC profits are tested.

It indicates that DC revenue mainly comes from its processing and customizing service. Through the sensitivity analysis, it is found that, the decrease of per unit DC picking and assorting cost contributes to the profit improvements for total system and almost all members whereas the decrease of per unit DC processing and customizing cost merely prospers the total system profit and DC profit. On the other hand, with the decrease of per unit DC picking and assorting cost in $G_{d}$ and with the increase of per unit DC processing and customizing cost in $E_{d k}$, DC gross profit from storage is decreased, which certifies that storage has degraded to the basic function of DC warehousing and DC profit comes more and more from value added service.

These conclusions present good theoretical and managerial insights that DC processing and customizing service for all kinds of products and all logistics services including both the traditional service and value added services for high value products should be strengthened, meanwhile cost savings must be achieved from picking/assorting service to devote to higher profits for both total system and all members. More attention should also be paid to preservative technology innovation in DC and DC processing and customizing cost control.

\section{Acknowledgement}

This research was supported by the National Natural Science Foundation of China Coordination and optimization of multi-echelon cold chain inventory system under compensation mechanism (71672166) and Shandong Social Science Planning Project Research on the governance structure and optimization of fresh overseas warehouse of cross border E-commerce (21CPYJ27)

\section{References}

1. Gustavsson, J., Cederberg, C., Sonesson, U., Van Otterdijk, R., Meybeck, A., 2011. Global food losses and food waste: extent, causes and prevention. FAO, Rome, Italy.

2. Wang, S., 2018. Developing value added service of cold chain logistics between China and Korea. Journal of Korea Trade, 22(3):247-264.

3. Bosona, T., Nordmark, I., Gebresenbet, G., Ljungberg, D., 2013. GIS-Based Analysis of Integrated Food Distribution Network in Local Food Supply Chain. International Journal of Business \& Management, 8 (17), 13-34.

4. Yang, P.C., Wee, H.M., 2000. Economic ordering policy of deteriorated item for vendor and buyer: an integrated approach. Production Planning \& Control, $11(5), 474-480$
5. Das, B.C., Das, B., Mondal, S.K., 2013. Integrated supply chain model for a deteriorating item with procurement cost dependent credit period. Computers \& Industrial Engineering, 64 (3), 788-796.

6. Rahdar, M., Nookabadi, A.S., 2014. Coordination mechanism for a deteriorating item in a two-level supply chain system. Applied Mathematical Modelling, 38 (11-12), 2884-2900.

7. Ghiami, Y., Williams, T., 2015. A two-echelon production-inventory model for deteriorating items with multiple buyers. International Journal of Production Economics, 159 (6), 233-240.

8. Chan, C.K., Wong, W.H., Langevin, A., Lee, Y.C.E., 2017. An integrated production-inventory model for deteriorating items with consideration of optimal production rate and deterioration during delivery. International Journal of Production Economics, 189 (7), 1-13.

9. Mohammadi, H., Ghazanfari, M., Pishvaee, M.S., Teimoury,E., 2019. Fresh-product supply chain coordination and waste reduction using a revenueand-preservation-technology-investment-sharing contract: A real-life case study. Journal of Cleaner Production, 213: 262-282.

10. Wang, S., Fan, X., Ma, X., Jiang, Y.,2020. A threestage cold chain inventory optimization model considering freshness and quantity loss of goods. Journal of System \&Management, 29(2): 399-416. 